\title{
Mit wissen kompakt punkten
}

\begin{abstract}
wissen kompakt ist das Fortbildungshighlight von Der Freie Zahnarzt. Jede Ausgabe bietet vier aktuelle und praxisnahe Fortbildungsbeiträge, mit denen Sie CME-Punkte (CME steht für ",continuing medical education “) sammeln können. Die Teilnahme erfolgt online über das Fortbildungsportal CME.springer.de des Springer Medizin Verlags, dem Kooperationspartner des Freien Verbandes Deutscher Zahnärzte e.V. (FVDZ). Die Teilnahme ist für Abonnenten und FVDZ-Mitglieder kostenlos.
\end{abstract}

\section{So einfach geht's!}

\section{> 1. Registrierung für Abonnenten und FVDZ-Mitglieder}

Um sich einmalig zu registrieren, klicken Sie auf der FVDZ-Homepage (www.fvdz.de, - Abb. 1) auf den Reiter „Fortbildung“ und dann auf den Punkt wissen kompakt. Gehen Sie nun auf „LernerfolgskontrollemitCME.springer.de“, loggen Sie sich ein und folgen Sie den Anweisungen im Registrierungsablauf. Ihre FVDZ-Mitgliedsnummer berechtigt Sie zur kostenlosen Teilnahme und wird automatisch an CME.springer.de übermittelt. Sie bekommen anschließend per E-Mail Ihre persönlichen Zugangsdaten zugeschickt. Bitte benutzen Sie diese für alle weiteren Teilnahmen zur Anmeldung (Login) auf CME.springer.de.

\section{Teilnehmen an Fortbildungs- einheiten aus wissen kompakt}

Nach Anmeldung auf CME.springer.de wählen Sie unter „Für Zahnärzte“ die Fortbildung aus, an der Sie teilnehmen möchten. Die Fortbildungseinheiten werden nach den Leitsätzen der Bundeszahnärztekammer zur zahnärztlichen Fortbildung einschließlich der Punktebewertung von BZÄK/DGZMK erstellt.

\section{(i) Hinweis}

Da sich das Angebot auf CME.springer.de hauptsächlich an Abonnenten der Facharztzeitschriften des Springer Medizin Verlags richtet, wirdhäufig Bezugauf, Abonnenten“ oder „Abonnementnummer" genommen. Hinsichtlich wissen kompakt sind diese Begriffe durch „FVDZ-Mitgliedsnummer“ bzw. „FVDZ-Mitgliedschaft“ zu ersetzen.

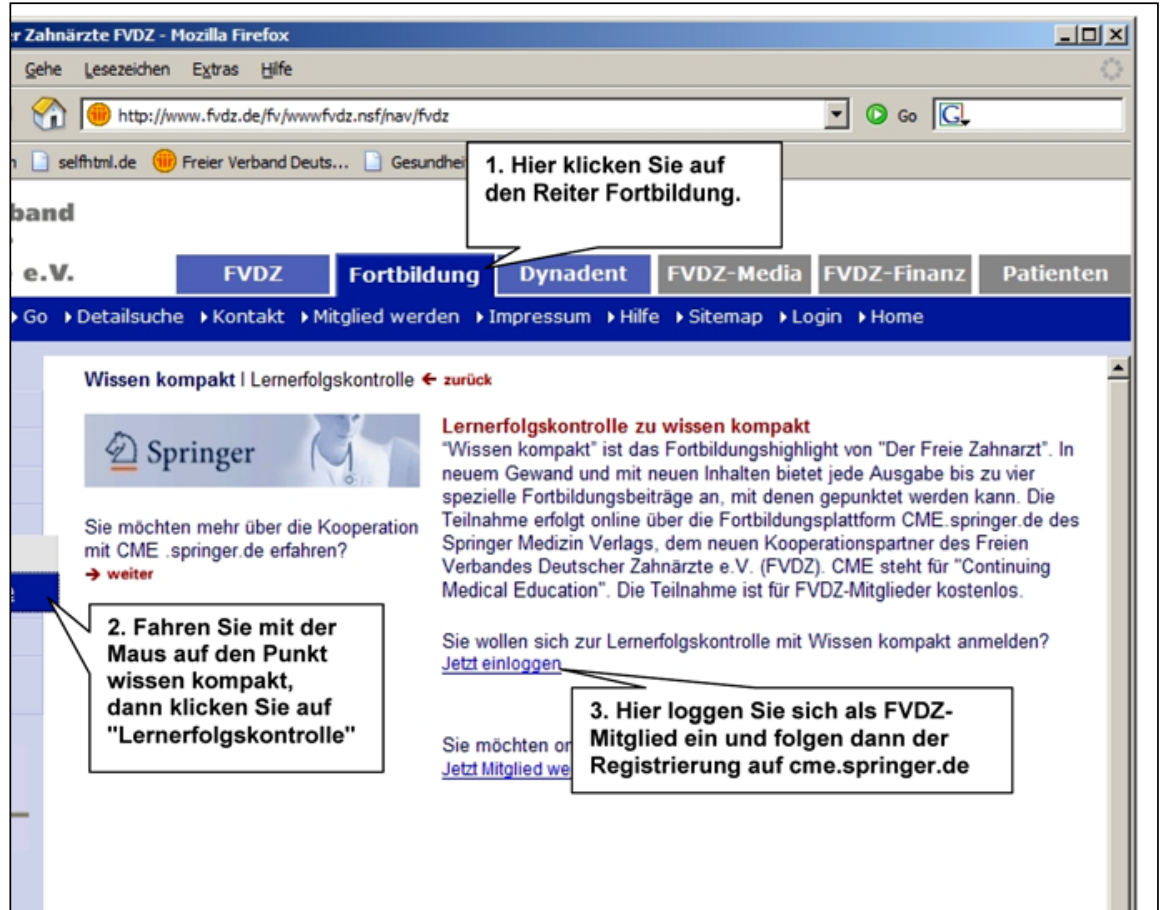

Abb. 1 A Teilnehmen und Punkte sammeln mit wissen kompakt

\section{Sie haben Fragen}

..zu einer FVDZ-Mitgliedschaft? Dann wenden Sie sich bitte an den FVDZ, Frau Schneider, Tel.: 0228-8557 41 oder E-Mail: gs@fvdz.de

...zu CME.springer.de oder der Teilnahme an den Fortbildungseinheiten aus wissen kompakt? Dann wenden Sie sich bitte an das CME-Helpdesk unter CME@springer.com oder Tel.: 06221-487 8926. 